\title{
STYLIZED FACTS OF THE DAILY, WEEKLY AND MONTHLY RETURNS ON BUCHAREST STOCK EXCHANGE DURING 2007-2012
}

\author{
Corina Maria Ene ${ }^{1}$ \\ Carmen Marilena Uzlau ${ }^{2}$ \\ Iulian Panait ${ }^{3}$
}

\begin{abstract}
Our paper documents a set of statistical properties of the monthly, weekly and daily returns for the most liquid 30 stocks traded on Bucharest Stock Exchange during 2007 - 2012 and also for 3 important Romanian stock market indices. Our results confirm the presence of most the stylized facts documented by Cont (2001) and other similar studies. Also we identify some particularities of the stock returns on the Romanian capital market which are useful both for local and foreign retail and institutional investors in their portfolio management decisions. In particular, we found that the monthly simple returns have an autocorrelation effect with 1-5lags, which is unusual for developed markets but was previously detected on other European emerging and frontier markets.
\end{abstract}

Keywords: stylized facts, stock returns, frontier markets

JEL codes: G01, G14, G15

\section{Introduction}

Our paper studies the particularities in monthly, weekly and daily returns for 30 companies and 3 market indices traded on Bucharest Stock Exchange during April 2007 - March 2012. We employ a comparative approach that is based on two different dimensions. First, we search for particularities of low frequency (monthly) returns that are different from ones of the high frequency (weekly and daily) returns. This kind of information is relevant for different categories of market players: speculators, mid-term investors and long term investors in their portfolio management decisions. For example the presence of volatility clustering stylized fact should determine a short term speculator and mid-term investor to exit the market at an early stage. Second, we present the specific statistical characteristics of the Romanian stocks and indices returns during the 2007-2009 financial and economic crisis and compare them with the evolution of the same assets after March 2009 (the moment when most stock indices registered a mid-term bottom). Our results emphasize the connection between market trend and asset correlation (high values for the correlation coefficients during down trends and lower values during up trends) which argues for the use of hedging as a better portfolio risk management technique in comparison with diversification across multiple industries.

For decades, a great number of individual investors, money managers and researches studied the statistical behavior of returns provided by different exchange or OTC traded assets. At the same time, from obvious practical reasons, the evolution of the stock markets during various types of crisis was investigated in detail by many researchers. Especially since 2008, many authors were interested to investigate the behavior of financial assets returns during the 2007-2009 stock market crisis.

\footnotetext{
${ }^{1}$ Hyperion University, Bucharest, Romania, e-mail: corina.maria.ene@gmail.com

${ }^{2}$ Hyperion University, Bucharest, Romania, e-mail: carmen_uzlau@yahoo.com

${ }^{3}$ Hyperion University, Bucharest, Romania, e-mail: iulian.panait@gmail.com
} 
In particular for investors and money managers who are preoccupied to create optimal portfolios, it is important and useful to know the statistical properties of assets returns, among which the most important ones are: the shape of the distribution (mean, variance, skewness and kurtosis), the changing pattern of the correlation coefficients, the absence or the existence of autocorrelation in simple returns and in squared returns. This will help them make better decisions about portfolio management and choosing the moments for taking and closing positions in the market.

Starting with the 1990's, the investment community became particularly interested in the frontier and emerging markets, searching for higher profits and optimal portfolio diversification. This study is important because offers some relevant details regarding the characteristics of stock market returns in Romania, during a very turbulent period of time.

The rest of the paper is organized as follows: section 2 presents the most relevant Romanian and international related studies; section 3 describes the data and the methodology; section 4 presents the results that were obtained; and section 5 summarizes the most important conclusions and proposes further directions of research in this field.

\section{Literature review}

Bekaert and Harvey (1997) investigated the differences in volatility across various emerging markets, in connection with the timing and scale of the implementation of capital market legal and administrative reforms. They show that, more often than not, capital market liberalizations conduct to an increase in the correlation of returns between the local market and the international markets. They also observe that capital market liberalizations cannot be made responsible for the increase of local market's volatility.

One year later, Bekaert et al. (1998) pointed out some clear differences in the evolution of financial assets returns on emerging markets: high variance, reduced correlations with other markets (both mature and emerging), high returns over long periods of time, a lot more predictability (in comparison with mature markets), much strongly influenced by external events.

Also, Bekaert et al. (2005) investigated contagion and proposed a two-factor asset pricing model with time-varying betas that can accommodate various levels of market integration. Subsequently, the authors use this model to forecast stock returns in Europe, Southeast Asia, and Latin America. At the same time, they describe how the intensity of regional markets' integration varies with time and they quantify the proportion of the total market volatility that is driven by each of the three following types of factors: global, regional, and local.

Cont (2001) introduces several stylized facts of logarithmic returns for financial assets. The number of markets and assets investigated by Cont is sufficient to consider that those statistical properties introduced by him can, in general, be found in most financial assets. He refers to the nonexistence of autocorrelations in simple returns, to the higher than normal probabilities for extreme returns (or thicker than normal tails of the distribution of returns - "heavy tails"), to the asymmetry of the distribution of returns, to the fact that standard deviation is usually higher than the expected return (the mathematical simple average of the observed returns), to the existence of autocorrelation for the squared returns and for variance, to the correlation dependence with time etc.

Gelos and Sahay (2001) studied the co-movements across stock markets from European transition economies and concluded that the correlations existing in the monthly stock indices can partly be determined by direct trade linkages.

Forbes and Rigobon (2002) found a high degree of co-movements among various stock markets during most periods of time. The authors name this behavior "interdependence". Previously, other researchers suggested that contagion (which is often defined as ,a significant increase in market co-movement after a shock to one country") frequently occurs during market (and also financial and economic) crises. Forbes and Rigobon's results are in contradiction with that 
belief. They argue that there was almost no statistically significant increase in the value of the unconditional correlation coefficients (i.e., no contagion) during the Asian crisis (1997), the Mexican devaluation (1994) and previous major U.S. market crash (1987).

Pop et al. (2009) described how Bucharest Stock Exchange evolved before the crises that occurred during 2007-2009 and identified the most important factors which determined its explosive returns. The paper also studied impact that this particular financial had on Bucharest Stock Exchange, emphasizing the causes which accentuated the market down trend.

Harrison et al. (2010) presented the stylized facts for the CEE stock market indices employing a panel data analysis. They concluded that most market indices' returns show evidence of stationarity. Also, the authors pointed out some particular features of index returns in these types of markets: a high degree of non-linearity and significant cross correlations.

Panait and Lupu (2009) also investigated the evolution of the Romanian capital market during the 2007-2009 crisis and suggested some measures that could facilitate its sustainable development. Also, Slavescu and Panait (2011) studied the volatility of the daily returns during 2007-2011 for many companies listed on Bucharest Stock Exchange and investigated the causal links with other international stock markets.

\section{Data and methodology}

This study was conducted on 30 most liquid companies traded on Bucharest Stock Exchange. The period investigated was April 2007 - March 2012. Also, we included into our study the most important 3 market indices: BET-C, BET and BET-FI. The official daily prices for these 33 assets were obtained from the official Bucharest Stock Exchange website.

After the preliminary processing of $\mathrm{data}^{4}$, we have transformed the price time series into return time series (in order to eliminate the non-stationarity) for all the 33 assets included into our study. According to Strong (1992, p.353), "there are both theoretical and empirical reasons for preferring logarithmic returns. Theoretically, logarithmic returns are analytically more tractable when linking together sub-period returns to form returns over long intervals. Empirically, logarithmic returns are more likely to be normally distributed and so conform to the assumptions of the standard statistical techniques." For the same reasons we used in our study logarithmic returns. This helped us to easily transform the daily returns into weekly and monthly returns (buy applying the summation operator) that were also needed in our study. The formula for logarithmic returns is as follows:

$$
\mathbf{R}_{i, t}=\operatorname{Ln}\left(\frac{P_{i, t}}{P_{i, t-1}}\right)
$$

where $\mathrm{Ri}, \mathrm{t}$ is the return of asset $\mathrm{i}$ in period $\mathrm{t} ; \mathrm{Pi}, \mathrm{t}$ is the price of asset $\mathrm{i}$ in period $\mathrm{t}$ and $\mathrm{Pi}, \mathrm{t}-1$ is the price of asset $i$ in period $t-1$.

The result of this data gathering and processing was a data base with 33 time series of logreturns, each with 1199 daily observations, 250 weekly observations and 58 monthly observations.

\footnotetext{
${ }^{4}$ The first step was to adjust all the prices with the (eventual) corporate events that took place during the investigated period (mainly dividends and share capital increases). In order to do that we deducted the eventual net dividends from price series previous to the ex-dividend date and we multiplied the price series previous to the registration date with the correction factor. The price time series for three market indices were already adjusted with corporate events by the stock exchange as part of the official index calculation methods.

The second step was to synchronize all the daily price observations in perfect chronologic order. For all the situations when an individual stock was not traded during any particular day but the stock exchange was open (so we had a price for the index at the end of that day), we filled the "blank" with the last available price from previous trading sessions (because since there were no transactions during that particular day we can assume that the last market price was the most relevant value for that asset during the no-trading period).
} 
For those 33 time series, each with daily, weekly and monthly frequency we used Eviews to compute the descriptive statistics. Also, we have calculated the matrix containing the unconditional correlation coefficients for each pair of assets, the vector containing the beta coefficients (from the Shape's Capital Assets Pricing Model) and we have investigated the autocorrelation and the partial autocorrelation of the simple returns and the squared returns (in order to determine if there are signs of volatility clustering). Of the many methods that are usually used for estimating the beta coefficient, we used the simple linear regression coefficient between each individual stock return (as dependent variables) and the main market index (in our case BET-C, as explanatory variable). We preferred this method because it also gave us t-statistic and $\mathrm{R}^{2}$ values that are helpful in order to better identify the statistical significance of the correlation.

$$
\mathrm{R}_{\mathrm{Ii}}=\alpha_{\mathrm{I}}+\beta_{\mathrm{I}} \mathrm{R}_{\mathrm{Mi}}+\varepsilon_{\mathrm{li}}
$$

For a better understanding of how the values of beta and of unconditional correlation coefficient change with time, we have also calculated them using a rolling window of 250 observations. For this analysis we used the Matlab code from Annex 1

\section{Results}

Based on the Table 1 (at the end of the article) we confirm that the long term average of the daily returns is statistically not different from zero. Also, we conclude that it is statistically not different from the value of the median. This finding was confirmed for all stocks and indices included in our study. We obtained arguments for these hypotheses from the t-statistic test and the Sign, Wilcoxon and Van der Wareden tests.

Also, from the descriptive statistics of the daily returns we can confirm that the standard deviation always has higher values in comparison with the average return and that the distribution is different from the theoretical normal distribution (as p-values for the Jarque-Bera tests are zero in all cases) exhibiting both skewness (mainly negative) and excess kurtosis (frequently near or above 7). These findings confirm similar conclusions of previous research conducted by other authors on various regional and global markets: Cont (2001), Bekaert et al. (1998), Harrison et al. (2010) etc.

Except for the remark regarding the long term average not being statistically significantly different from zero, all the above conclusions are also valid for the time series of weekly and monthly returns. Particularly in the case of the monthly returns we observe that the values of kurtosis are significantly lower in comparison with the daily and weekly returns. We also observe that the values of the Jarque Berra tests are lower and their $\mathrm{p}$-value is above $1 \%$ for 7 out of the 33 time series. This leads us to the conclusion that we can only in part confirm the stylized fact that lower frequencies of returns have distributions closer to the form of the theoretical normal distribution (Cont, 2001), because in 26 out of the 33 time series that we used the distribution of the monthly returns is still different from the normal distribution. For example, Figure 1 presented below show that the distributions of returns in the case of the three market indices included into our study are different from the normal distribution for all the three frequencies investigated (daily, weekly and monthly). It also confirms the presence of the "fat tails" stylized fact (higher probability for extreme negative returns in comparison with the theoretical normal distribution) documented by Cont (2001).

Because the period that we investigated includes both a crash cycle (with significant and long declines during Jun.2007 - Feb.2009) and also an accelerated recovery phase (between Mar.2009 - Mar.2012), we were interested to study the evolution of standard deviation, beta coefficients, unconditional coefficients and the range of returns for those two different stages. Table 2 (at the end of this article) show that for all the 33 assets, the maximum net returns during a trading session and the standard deviations for the respective period were lower during the up-trend (Mar.2009 - Mar.2012) in comparison with the down-trend (Jun.2007-Feb.2009). This gives us arguments to confirm the conclusions of other studies based on various different markets, according 
to which the volatility is amplified during periods of market downturns: Harrison et al. (2010), Bekaert and Harvey (1997). Also, our results confirm that most of the statistical measures of the evolution of financial assets' returns are dependent with time and general market circumstances.
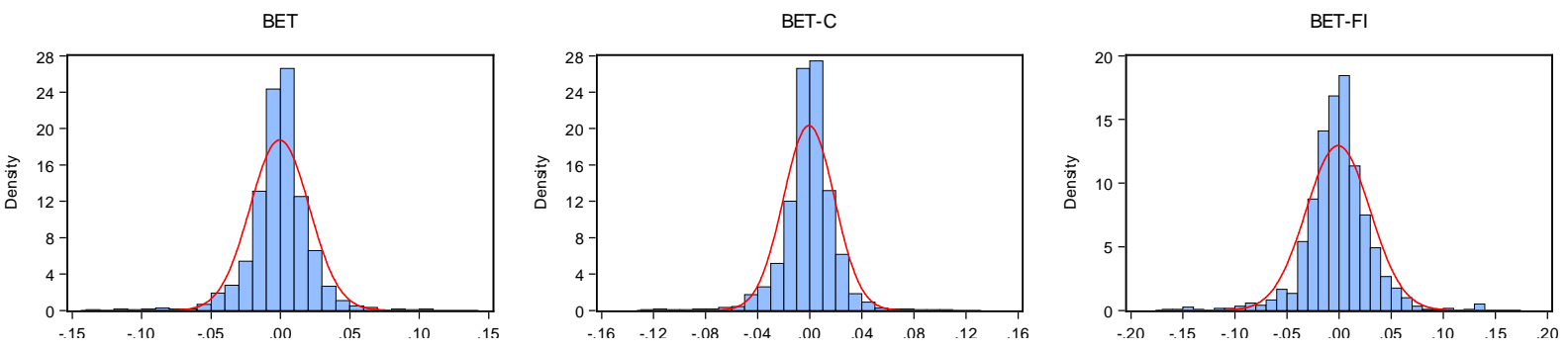

BET
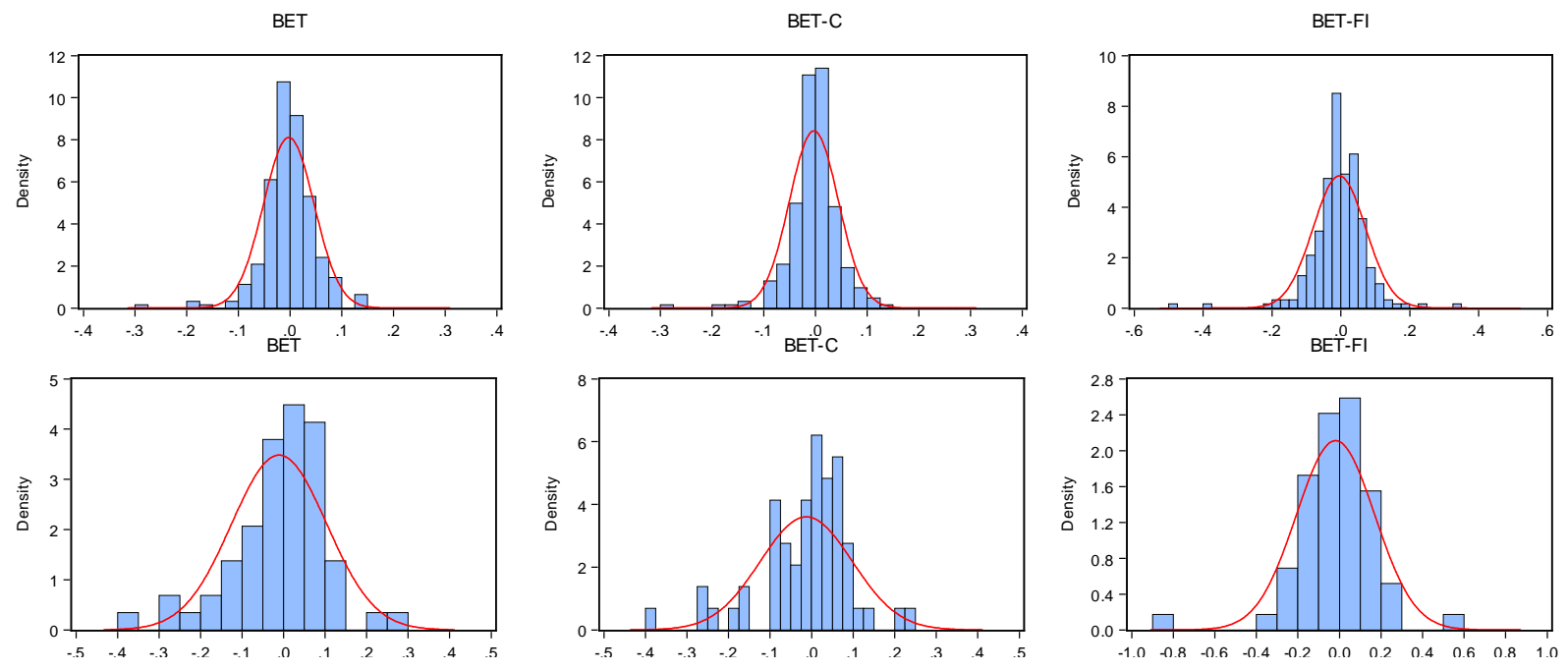

Figure no. 1. - Comparison between actual probability distributions and the theoretical normal distribution for the daily, weekly and monthly returns of the three market indices

Source: Bucharest Stock Exchange, calculations made by the authors

At the same time, the Table 2 presented at the end of this article confirms the presence of the "leverage effect", showing an increase in the maximum daily amplitude of variation during the same periods when the standard deviation is also higher. 


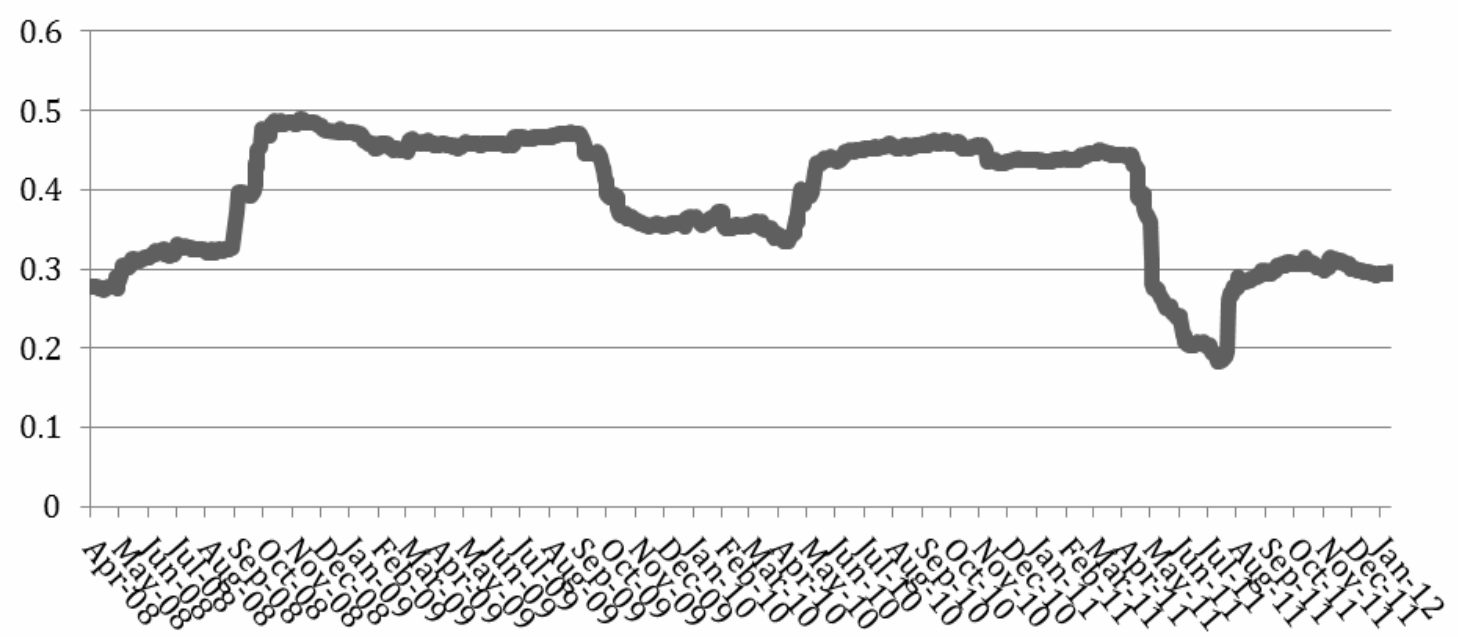

Figure no.2 - Evolution of the average 250 days unconditional correlation coefficient across all the possible pairs from the 30 individual stocks included into the study

Source: Bucharest Stock Exchange, calculations made by the authors

In order to further highlight the evolution of the beta coefficients and of the unconditional correlation coefficients we studied the behavior of a "rolling" sample size of 250 days (the equivalent of one year of stock trading). In the Figure 2 we show the average unconditional correlation coefficient across all the 870 possible pairs of assets for the investigated period. The chart demonstrates that the average value of the correlation coefficients vary with time. Also we can observe that its evolution is likely to be influenced by the stock market condition. We observed that during the periods of declining markets (Jun.2007-Feb.2009) the intensity of correlations between assets was growing, while during periods of positive evolution (Mar.2009 - Mar.2012) the correlation coefficients are declining.

We concluded our research with a test of autocorrelation of simple returns and of squared returns. In order to achieve that we used AC ("autocorrelation") functions and PAC ("partialautocorrelation"), applied for detecting the possible correlations between the current returns/squared returns and each of the previous 100 past returns/squared returns, for all the 33 assets that were analyzed.

Because when the long term average of the returns is close to zero (as it is the case for the daily returns) the one period variance can be approximated by the squared return of that period. This explained the reason why we were interested in the squared daily returns: they provide a good approximation for the intraday variance. Since we found significant autocorrelation of squared returns for all our 33 assets, this means we can also confirm the stylized fact of „volatility clustering" which can be demonstrated by the charts presented below.

Our results show that the high frequency simple returns are not auto-correlated. Surprisingly, most of the 33 assets exhibit statistically significant auto-correlation for the low frequency simple returns (in our case the monthly returns). This observation is valid both for individual assets and for market indices.

For all the 33 assets and for all three frequencies investigated (daily, weekly and monthly) we have found statistically significant autocorrelation and partial autocorrelation of the squared returns which confirms the presence of "volatility clustering".

The "volatility clustering" property demonstrated by Figure 3 from above is important for investors and money managers because allows the usage ARIMA and GARCH models for the prediction of future volatility of assets and portfolio, an important tool that can be used in order to manage the total risk of an investment or portfolio of investments. 


\section{Conclusions}

The conclusions derived from our research generally confirm the results of previous research conducted by various authors (already mentioned above inside the literature review section) for prior periods of time and for other regional markets.

Our results show that the average of the high frequency returns (daily returns) and lower frequency (monthly returns) are generally not statistically significantly different from zero (for a maximum error threshold of $1 \%$ ).

Also, we confirm that volatility (measured by standard deviation indicator) has values higher than average for both individual stocks and market indices and for all three frequencies investigated.

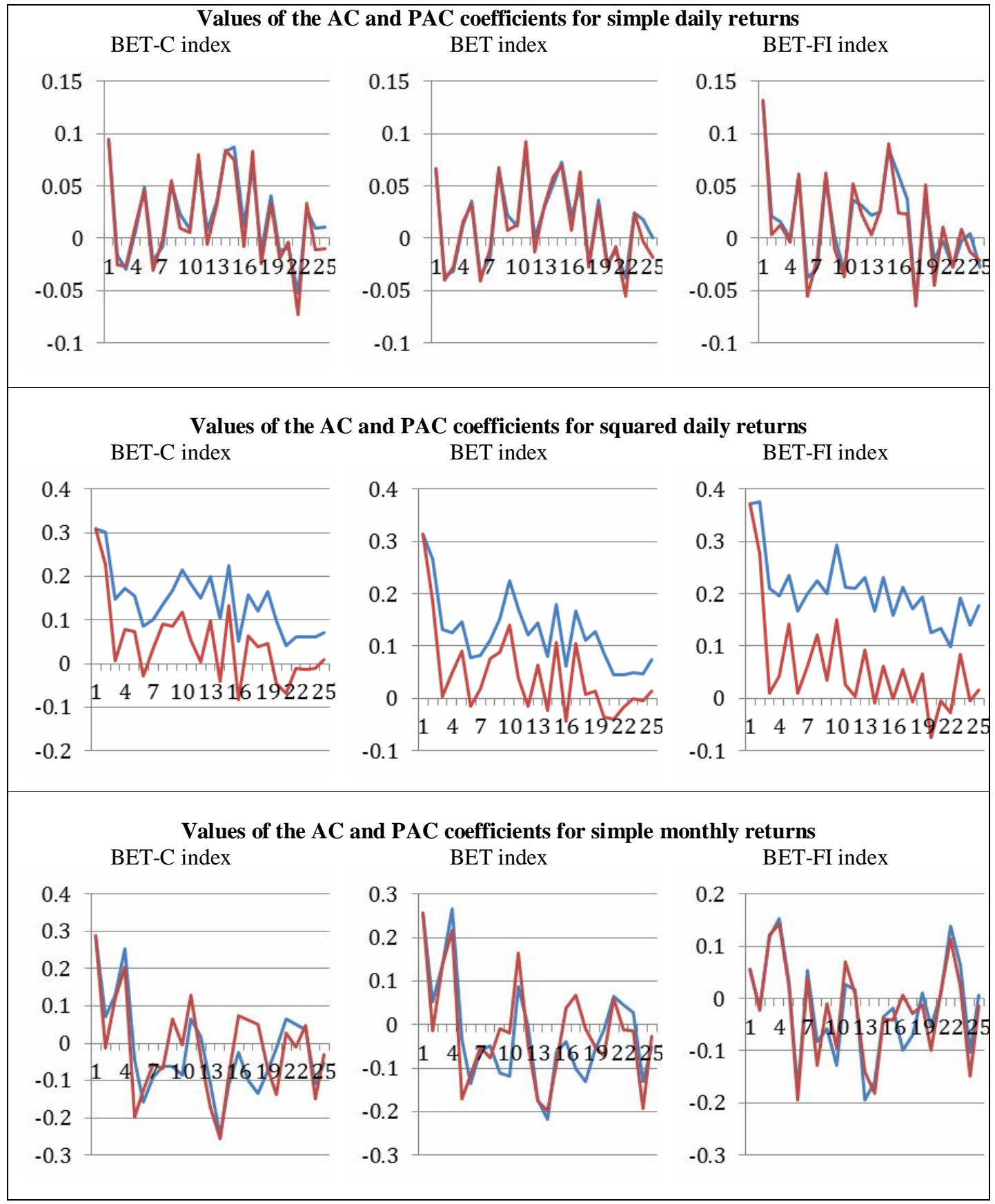




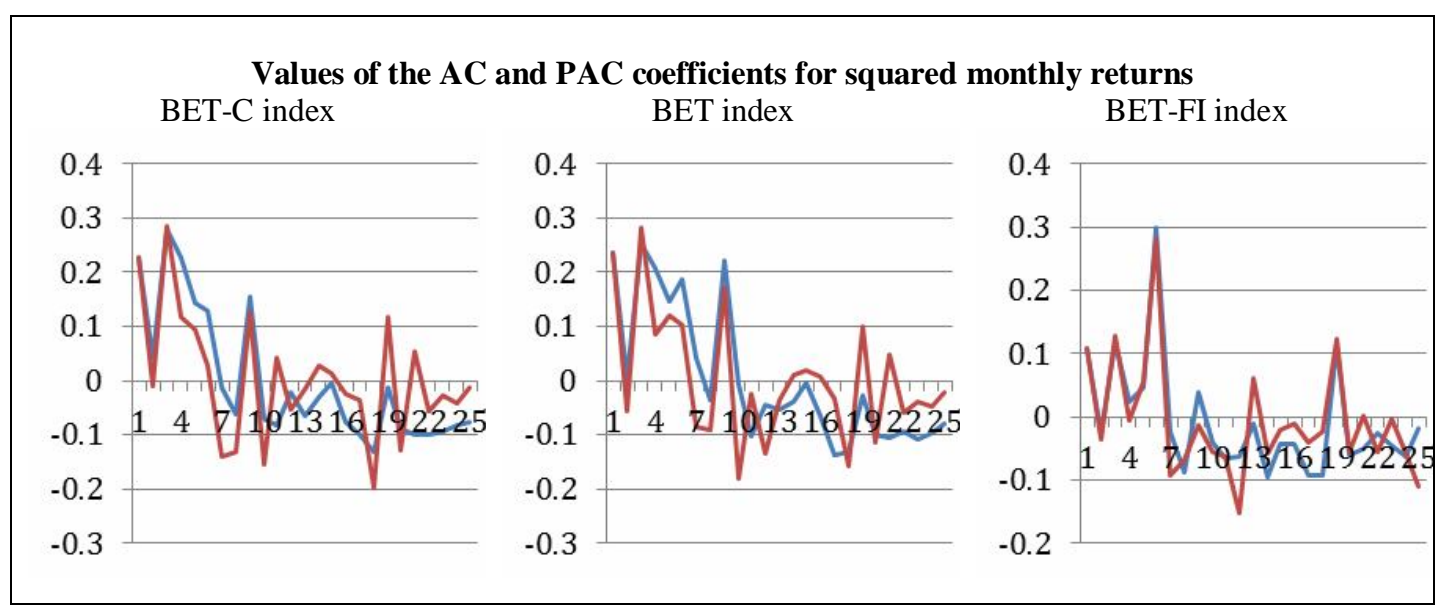

Figure no. 3

At the same time, our study confirms the hypothesis that distribution of daily returns is significantly different from the theoretical normal distribution for both individual assets and indices. We found that this conclusion is valid for all three types of frequencies, which shows a clear particularity of the Romanian markets, because other authors that investigated different markets and time frames found that lower frequency returns (for example monthly returns) have forms of distributions than are close to the normal distribution. In this particular, this present study shows that the distribution of monthly returns of frontier markets deviate significantly from the normal distribution.

We found that most of the assets investigated presented negative asymmetry during 20072012, both individual stocks as well as market indices, for all frequencies. This result confirms that the probability of negative returns of high magnitude is higher than the probability of positive returns of similar magnitude.

Our results confirmed the hypothesis that kurtosis is higher than 3 for the series of daily and weekly returns, both individual assets and indices. In terms of monthly returns we found that kurtosis values are generally close to the value 3 (specific to normal distribution). We concluded that for daily and weekly returns the property of 'thick tails' is validated, which means a higher probability than that derived from the normal distribution for returns far beyond the average.

For all the frequencies investigated, our study validates the property of "leverage", i.e. the periods of high volatility (standard deviation) are accompanied by increased amplitude of returns compared with the ones from periods of low volatility.

Our study validates the hypothesis of time dependence in the intensity of the unconditional correlations between assets. Also, the study confirms that during periods of high volatility there is an increase in the intensity of the correlations between most pairs of assets, while the low volatility periods are characterized by a decrease in the intensity of the correlations between assets.

Regarding the AC and PAC coefficients for simple and squared returns, the daily and weekly time series confirm the absence of autocorrelation in simple returns and the presence of autocorrelation of squared returns. Surprisingly, our data shows that the monthly simple returns indicate an autocorrelation effect with 1-5 lags. Form these results and from other related studies (Panait and Constantinescu, 2012) we conclude that this effect is especially noticeable in the case of frontier markets.

Our results can be used by various types of investors in their portfolio management decisions. For example, because the monthly returns show signs of autocorrelation ARIMA models could be used for predicting asset returns over the next period. Also, the dependence of the correlation coefficients with the market trend should determine investors to use hedging rather than 
diversification as the most important tool of risk management. The presence of volatility clustering shows the usefulness of GARCH models for estimating the volatility over the next period and also should determine the risk adverse investors to exit the market at early signs of turbulence because that kind of market behavior is likely to be more than a single and temporary event.

\section{References}

1. Bekaert G., Harvey C.R., 1997. Emerging Equity market volatility, Journal of Financial Economics, issue 43, pp. 29-77

2. Bekaert G., Harvey C.R., Ng A., 2005. Market integration and contagion, Journal of Business, vol. 78, issue 1, pp. 39-69

3. Bekaert G.E., Erb C.B., Harvey C.R., Vyskanta T.E., 1998. Distribution Characteristics of Emerging Market Returns and Asset Allocation, Journal of Portfolio Management, issue 24, pp.102-116

4. Conover C., Mitchell J.G.R., Johnson R.R., 2002. Emerging Markets: When Are They Worth It?, Financial analysts Journal, pp.86-95

5. Cont R., 2001. Empirical properties of asset returns: stylized facts and statistical issues, Quantitative Finance, vol.1, issue 2, pp. 223-236

6. Forbes K.J., Rigobon R., 2002. No contagion, only interdependence: Measuring stock market co-movements, Journal of Finance, vol. 57, issue 5, pp. 2223-2261

7. Gelos R.G., Sahay R., 2001. Financial market spillovers in transition economies, Economics of Transition, vol. 9, issue 1, pp. 53-86

8. Harrison B., Lupu R., Lupu I., 2010. Statistical Properties of the CEE Stock Market Dynamics. A Panel Data Analysis, The Romanian Economic Journal, issue 37, pp. 41-54

9. Hartmann P., Straetmans S., de Vries C.G., 2004. Asset market linkages in crisis periods, Review of Economics and Statistics, vol. 86, issue 1, pp. 313-32611

10. Panait I., Lupu I., 2009. The behavior of the Bucharest Stock Exchange during the current financial markets crisis and proposed measures for its sustainable development, Spiru Haret University Annales - Economic Series, vol.1, issue 1, pp.73-80

11. Panait I., Constantinescu A., 2012. Stylized Facts Of The Daily And Monthly Returns For The European Stock Indices During 2007-2012, Journal of Applied Quantitative Methods, vol.7, issue 3, forthcoming

12. Pop C., Curutiu C., Dumbrava P., 2009. Bucharest Stock Exchange - The effects of the current financial crisis, Interdisciplinary Management Research V, pp. 805-818

13. Slăvescu E.O., Panait I., 2011. Volatility and Causality Study of the Daily Returns on the Bucharest Stock Exchange during 2007-2011, International Conference The KnowledgeBased Organization - Economic, Social and Administrative Approaches to the KnowledgeBased Organization, Nicolae Balcescu Land Forces Academy, Sibiu, published in Proceeding of the 17th International Conference The Knowledge-Based Organization Economic, Social and Administrative Approaches to the Knowledge-Based Organization, Nicolae Balcescu Land Forces Academy Publishing House, Sibiu, pp. 292-300

14. Strong N., 1992. Modeling Abnormal Returns: A Review Article, Journal of Business Finance and Accounting, vol. 19, issue 4, pp. 533-553 
Matlab code for calculating rolling window unconditional correlation coefficient

Annex 1

function beta $=$ rollingBeta(rets, window)

$[\mathrm{N}, \mathrm{M}]=\operatorname{size}($ rets $)$;

beta $=\operatorname{nan}(\mathrm{N}, \mathrm{M}-1)$;

for $\mathrm{i}=$ window $+1: \mathrm{N}$

for $\mathrm{j}=2: \mathrm{M}$

$\operatorname{betaTS}(\mathrm{i}, \mathrm{j}-1)=\operatorname{rets}(\mathrm{i}-$ window:i, 1) $\backslash$ rets(i-window:i, j);

end

end

where rets is a matrix of 33 columns and 1199 rows and window is the size of the rolling window.

Table no.1.

Descriptive statistics for the series of daily returns (Apr.2007 - Mar.2012)

\begin{tabular}{|c|c|c|c|c|c|c|c|c|c|}
\hline Symbol & Mean & Median & Max & Min & Std. Dev. & Skewness & Kurtosis & J-B p-val & Beta \\
\hline ALT & -0.0016 & 0.0000 & 0.1398 & -0.2386 & 0.0388 & -0.01 & 7.51 & 0 & 0.91 \\
\hline ALU & -0.0018 & 0.0000 & 0.1372 & -0.1600 & 0.0342 & -0.58 & 7.83 & 0 & 0.84 \\
\hline AMO & -0.0011 & 0.0000 & 0.1398 & -0.2417 & 0.0473 & 0.16 & 5.98 & 0 & 1.19 \\
\hline ATB & -0.0013 & 0.0000 & 0.1386 & -0.1760 & 0.0289 & -0.57 & 10.71 & 0 & 1.00 \\
\hline AZO & 0.0016 & 0.0000 & 0.3358 & -0.2004 & 0.0429 & 0.61 & 9.53 & 0 & 1.03 \\
\hline $\mathrm{BCC}$ & -0.0020 & 0.0000 & 0.1398 & -0.1625 & 0.0282 & 0.00 & 10.92 & 0 & 0.72 \\
\hline BET & -0.0005 & 0.0002 & 0.1056 & -0.1312 & 0.0213 & -0.56 & 8.62 & 0 & 1.06 \\
\hline BET_C & -0.0006 & 0.0001 & 0.1089 & -0.1212 & 0.0196 & -0.71 & 9.47 & 0 & 1.00 \\
\hline BET_FI & -0.0009 & -0.0005 & 0.1383 & -0.1608 & 0.0308 & -0.24 & 7.78 & 0 & 1.28 \\
\hline $\mathrm{BIO}$ & -0.0011 & 0.0000 & 0.1398 & -0.4136 & 0.0354 & -1.75 & 23.60 & 0 & 1.27 \\
\hline BRD & -0.0006 & 0.0000 & 0.1398 & -0.1874 & 0.0281 & -0.47 & 9.12 & 0 & 1.22 \\
\hline BRK & -0.0025 & 0.0000 & 0.1588 & -0.3960 & 0.0429 & -1.20 & 14.88 & 0 & 1.35 \\
\hline CMP & -0.0010 & 0.0000 & 0.1384 & -0.3773 & 0.0399 & -1.15 & 14.16 & 0 & 1.21 \\
\hline COMI & -0.0019 & 0.0000 & 0.2231 & -0.4012 & 0.0412 & -1.06 & 14.89 & 0 & 1.20 \\
\hline DAFR & -0.0022 & 0.0000 & 0.1398 & -0.1620 & 0.0360 & -0.12 & 6.70 & 0 & 1.23 \\
\hline ELMA & -0.0014 & 0.0000 & 0.2231 & -1.1360 & 0.0526 & -10.31 & 209.69 & 0 & 1.02 \\
\hline IMP & -0.0029 & 0.0000 & 0.1501 & -0.6224 & 0.0458 & -2.78 & 37.92 & 0 & 1.23 \\
\hline OLT & 0.0009 & 0.0000 & 0.1398 & -0.2206 & 0.0498 & 0.15 & 5.51 & 0 & 1.11 \\
\hline PTR & -0.0014 & 0.0000 & 0.1398 & -0.6931 & 0.0406 & -4.32 & 77.19 & 0 & 1.03 \\
\hline $\mathrm{RRC}$ & -0.0008 & 0.0000 & 0.1624 & -0.1625 & 0.0338 & 0.49 & 7.61 & 0 & 0.95 \\
\hline SCD & -0.0005 & 0.0000 & 0.1395 & -0.1619 & 0.0298 & 0.34 & 10.17 & 0 & 0.69 \\
\hline SIF1 & -0.0010 & 0.0000 & 0.1398 & -0.1611 & 0.0337 & -0.22 & 6.90 & 0 & 1.30 \\
\hline SIF2 & -0.0007 & 0.0000 & 0.1394 & -0.1625 & 0.0342 & -0.23 & 6.92 & 0 & 1.38 \\
\hline SIF3 & -0.0015 & 0.0000 & 0.1391 & -0.6908 & 0.0398 & -4.46 & 79.10 & 0 & 1.29 \\
\hline SIF4 & -0.0009 & 0.0000 & 0.1394 & -0.1606 & 0.0314 & -0.09 & 7.49 & 0 & 1.19 \\
\hline SIF5 & -0.0009 & 0.0000 & 0.1394 & -0.1613 & 0.0334 & -0.21 & 6.97 & 0 & 1.32 \\
\hline SNO & -0.0014 & 0.0000 & 0.1398 & -0.1625 & 0.0372 & 0.22 & 7.15 & 0 & 0.84 \\
\hline SNP & -0.0004 & 0.0000 & 0.1374 & -0.1621 & 0.0283 & -0.29 & 8.59 & 0 & 1.17 \\
\hline SOCP & 0.0002 & 0.0000 & 0.1398 & -0.1552 & 0.0356 & 0.43 & 6.49 & 0 & 0.50 \\
\hline TBM & -0.0023 & 0.0000 & 0.1398 & -0.1589 & 0.0368 & 0.10 & 6.78 & 0 & 0.97 \\
\hline
\end{tabular}




\begin{tabular}{|c|c|c|c|c|c|c|c|c|c|}
\hline TEL & -0.0008 & 0.0000 & 0.1398 & -0.1531 & 0.0267 & -0.07 & 8.74 & 0 & 1.03 \\
\hline TLV & -0.0020 & 0.0000 & 0.1324 & -0.8679 & 0.0403 & -10.28 & 202.19 & 0 & 1.02 \\
\hline VNC & -0.0006 & 0.0000 & 0.1392 & -0.1606 & 0.0343 & 0.01 & 6.81 & 0 & 0.77 \\
\hline
\end{tabular}

Table no.2.

Comparative study of the volatility (maximum daily variation and standard deviation), skewness and beta coefficients during general market up-trend and down-trend periods

\begin{tabular}{|c|c|c|c|c|c|c|c|c|}
\hline \multirow[b]{2}{*}{ Symbol } & \multicolumn{4}{|c|}{ During the 2007-2009 market crisis } & \multicolumn{4}{|c|}{ During the 2009-2012 market up-trend } \\
\hline & Max variation & Std. Dev. & Skewness & Beta & Max variation & Std. Dev. & Skewness & Beta \\
\hline ALT & 0.2386 & 0.0449 & -0.4811 & 0.96 & 0.1398 & 0.0348 & 0.6460 & 0.87 \\
\hline ALU & 0.1600 & 0.0403 & -0.8140 & 0.77 & 0.1600 & 0.0306 & -0.1274 & 0.90 \\
\hline $\mathrm{AMO}$ & 0.2417 & 0.0552 & -0.0964 & 1.30 & 0.1625 & 0.0433 & 0.4987 & 1.09 \\
\hline ATB & 0.1625 & 0.0345 & -0.6956 & 1.06 & 0.1760 & 0.0261 & -0.2476 & 0.95 \\
\hline $\mathrm{AZO}$ & 0.2004 & 0.0583 & 0.0850 & 1.23 & 0.3358 & 0.0325 & 2.2303 & 0.83 \\
\hline $\mathrm{BCC}$ & 0.1625 & 0.0328 & -0.4103 & 0.73 & 0.1398 & 0.0258 & 0.6796 & 0.72 \\
\hline BET & 0.1312 & 0.0258 & -0.6058 & 1.04 & 0.1161 & 0.0187 & -0.1435 & 1.09 \\
\hline BET_C & 0.1212 & 0.0243 & -0.6857 & 1.00 & 0.1050 & 0.0168 & -0.2745 & 1.00 \\
\hline BET_FI & 0.1608 & 0.0360 & -0.3426 & 1.25 & 0.1497 & 0.0280 & 0.0997 & 1.32 \\
\hline $\mathrm{BIO}$ & 0.4136 & 0.0462 & -2.1432 & 1.33 & 0.1479 & 0.0277 & 0.6347 & 1.20 \\
\hline BRD & 0.1874 & 0.0346 & -0.5739 & 1.24 & 0.1398 & 0.0239 & -0.0765 & 1.19 \\
\hline BRK & 0.3960 & 0.0537 & -1.7171 & 1.33 & 0.1608 & 0.0364 & 0.2917 & 1.35 \\
\hline CMP & 0.2877 & 0.0429 & -1.2147 & 1.15 & 0.1620 & 0.0363 & 0.2380 & 1.26 \\
\hline COMI & 0.1625 & 0.0454 & -0.4707 & 1.28 & 0.4012 & 0.0373 & -1.5718 & 1.12 \\
\hline DAFR & 0.1620 & 0.0403 & -0.5249 & 1.13 & 0.1618 & 0.0335 & 0.3658 & 1.37 \\
\hline ELMA & 1.1360 & 0.0720 & -9.5868 & 1.10 & 0.6974 & 0.0390 & -7.4177 & 0.94 \\
\hline IMP & 0.6224 & 0.0600 & -3.5042 & 1.22 & 0.1610 & 0.0356 & 0.3119 & 1.21 \\
\hline OLT & 0.2206 & 0.0442 & -0.2983 & 0.97 & 0.1625 & 0.0532 & 0.2379 & 1.24 \\
\hline PTR & 0.6931 & 0.0546 & -5.2910 & 1.15 & 0.1495 & 0.0302 & 0.6312 & 0.92 \\
\hline RRC & 0.1625 & 0.0392 & 0.2470 & 1.10 & 0.1624 & 0.0313 & 0.7925 & 0.81 \\
\hline SCD & 0.1607 & 0.0359 & 0.1127 & 0.87 & 0.1619 & 0.0266 & 0.8228 & 0.49 \\
\hline SIF1 & 0.1611 & 0.0385 & -0.3262 & 1.29 & 0.1431 & 0.0313 & 0.0392 & 1.32 \\
\hline SIF2 & 0.1625 & 0.0385 & -0.4889 & 1.31 & 0.1594 & 0.0318 & 0.1616 & 1.45 \\
\hline SIF3 & 0.1623 & 0.0393 & -0.4613 & 1.23 & 0.1504 & 0.0312 & 0.1243 & 1.37 \\
\hline SIF4 & 0.1606 & 0.0363 & -0.0987 & 1.20 & 0.1449 & 0.0287 & 0.0620 & 1.19 \\
\hline SIF5 & 0.1613 & 0.0377 & -0.4352 & 1.25 & 0.1514 & 0.0311 & 0.1622 & 1.39 \\
\hline SNO & 0.1625 & 0.0480 & 0.2566 & 0.95 & 0.1404 & 0.0293 & 0.0685 & 0.72 \\
\hline SNP & 0.1621 & 0.0355 & -0.2806 & 1.20 & 0.1592 & 0.0239 & 0.0056 & 1.16 \\
\hline SOCP & 0.1552 & 0.0341 & 0.5654 & 0.39 & 0.1398 & 0.0369 & 0.4531 & 0.64 \\
\hline TBM & 0.1576 & 0.0403 & -0.1635 & 0.96 & 0.1589 & 0.0358 & 0.3768 & 1.00 \\
\hline TEL & 0.1531 & 0.0327 & 0.1223 & 1.12 & 0.1456 & 0.0233 & -0.1256 & 0.95 \\
\hline TLV & 0.8679 & 0.0543 & -11.6090 & 0.87 & 0.2360 & 0.0291 & -0.7364 & 1.18 \\
\hline VNC & 0.1606 & 0.0417 & 0.0000 & 0.74 & 0.1603 & 0.0299 & 0.1386 & 0.81 \\
\hline
\end{tabular}

Source: Bucharest Stock Exchange, calculations made by the authors 